\title{
PENGARUH PENAMBAHAN ASPAL EMULSI TERHADAP NILAI CBR TANAH GLEE GEUNTENG ACEH BESAR
}

\author{
Ani Safitri ${ }^{1{ }^{* *}}$ Banta Chairullah $\mathbf{M}^{2}$ Halida Yunita ${ }^{3}$ \\ ${ }^{1}$ Mahasiswa, Jurusan Teknik Sipil, Universitas Syiah Kuala, Banda Aceh 23111, Indonesia \\ 2,3 Jurusan Teknik Sipil, Universitas Syiah Kuala, Banda Aceh 23111, Indonesia. \\ Email: safitri20sa@gmail.com
}

\begin{abstract}
Natural soil sometimes cannot be directly used as construction material or where buildings are built. It caused by various limitations of natural soil, especially clay. Efforts that can be made to improve soil properties are using stabilization techniques by mixing additive materials in the natural soil. In this study used emulsion asphalt additives from PT. Perdana Dinamika Persada, type CSS-1h (Cationic slow setting). While the soil came from Glee Geunteng, Peukan Bada, Aceh Besar. The location was chosen because the soil is often used as a landfill for building and road construction. This research was conducted by mixing natural soil and asphalt emulsion at variations of $0 \%, 3 \%, 6 \%, 9 \%$, and $12 \%$ of the dry weight of the soil. Tests carried out in this research consisted of specific gravity, liquid limit, plastic limit, grain distribution, and compaction (standard projector), and CBR testing. Glee Geunteng soil according to AASHTO classification belongs to group A-6 (2) and according to USCS belongs to $S C$ group, where the plastic index is $12.65 \%$. The results showed that in natural soils up to the addition of $12 \%$ emulsion asphalt the CBR value decreased from $35.96 \%$ to $8.71 \%$.
\end{abstract}

Keywords: stabilization, Glee Geunteng soil, emulsion asphalt, CBR.

\begin{abstract}
Abstrak
Tanah yang ada di alam terkadang tidak dapat langsung digunakan sebagai bahan bangunan atau tempat berdirinya bangunan. Hal ini dikarenakan dengan berbagai keterbatasan sifat yang dimiliki oleh tanah tersebut terutama tanah lempung. Usaha yang dapat dilakukan untuk memperbaiki sifat tanah yaitu dengan cara teknik stabilisasi yaitu dengan mencampur bahan-bahan additive dalam tanah asli. Pada penelitian ini digunakan bahan aditif aspal emulsi yang berasal dari PT. Perdana Dinamika Persada, tipe CSS-1h (Cationic slow setting). Tanah yang digunakan dalam penelitian berasal dari Glee Geunteng Kecamatan Peukan Bada Kabupaten Aceh Besar. Pemilihan lokasi ini karena tanah tersebut sering digunakan sebagai bahan timbunan bangunan dan badan jalan. Penelitian ini dilakukan dengan cara pencampuran tanah asli dan aspal emulsi pada variasi 0\%, 3\%, 6\%, 9\%, dan $12 \%$ dari berat kering tanah. Pengujian yang dilakukan pada penelitian ini terdiri dari pengujian berat jenis, batas cair, batas plastis, pembagian butiran, dan pemadatan (standard proctor), serta pengujian CBR. Tanah Glee Geunteng yang diteliti ini menurut klasifikasi AASHTO tergolong kedalam kelompok A-6 (2) dan menurut USCS termasuk ke dalam golongan SC, di mana indeks plastisnya 12,65\%. Hasil penelitian memperlihatkan bahwa pada tanah asli hingga penambahan aspal emulsi 12\% nilai CBR mengalami penurunan dari 35,96\% menjadi 8,71\%.
\end{abstract}

Kata kunci : stabilisasi, tanah Glee Geunteng, aspal emulsi, CBR.

\section{Pendahuluan}

Tanah memiliki peranan yang sangat penting dalam pekerjaan teknik sipil, baik itu untuk konstruksi bangunan maupun konstruksi jalan. Tanah adalah material yang tersusun dari butir-butir yang tidak terkait antara satu dengan yang lain yang di antaranya terdapat rongga-rongga berisi udara dan air. Tanah mempunyai peranan yang sangat penting, yaitu sebagai tempat berdirinya suatu konstruksi atau sebagai bahan konstruksi. Tanah yang akan digunakan untuk bahan konstruksi harus memiliki kekuatan yang cukup untuk menahan beban. Beberapa hal yang perlu diperhatikan dalam penggunaan tanah untuk kontruksi, terutama bila tanah tersebut tergolong pada tanah lempung, misalnya memiliki sifat plastis dan kembang-susut yang tinggi. Tanah lempung terdiri atas butiran yang sangat kecil dan memiliki sifat kohesi, sifat kohesi berarti butiran-butiranya saling menempel dan sangat peka terhadap pengaruh kadar air. Dalam keadaan kering tanah lempung akan sangat keras dan kuat, tetapi pada keadaan basah tanah mengembang, sehingga menyebabkan daya dukungnya sangat lemah. Kemampuan tanah dalam menerima beban sangat tergantung pada gradasi dan perilaku tanah terhadap perubahan kadar air.

Salah satu usaha untuk meningkatkan kekuatan tanah dapat dilakukan dengan cara teknik stabilisasi, yang lebih dikenal dengan istilah soil stabilization. Stabilisasi adalah usaha memperbaiki kemampuan daya dukung tanah dengan menggunakan bahan 
aditif atau dengan usaha pemadatan. Stabilisasi dapat dilakukan dengan dua cara, yaitu stabilisasi mekanis yang dilakukan dengan cara memadatkan tanah dengan menggunakan peralatan mekanis, dan stabilisasi kimiawi yaitu mencampur tanah dengan bahan stabilisasi seperti semen, kapur, abu terbang (fly ash) atau bahan aditif lainnya. Pemilihan bahan stabilisasi yang digunakan di suatu tempat sangat tergantung pada jenis tanah dan ketersediaan bahan serta tujuan penggunaannya. Pada penelitian ini dilakukan stabilisasi kimiawi.

Pada penelitian ini, sampel tanah yang digunakan adalah tanah terganggu (disturbed), yang berasal dari Desa Glee Geunteng Kabupaten Aceh Besar. Pemilihan ini karena tanah di lokasi tersebut sering digunakan sebagai bahan timbunan bangunan dan badan jalan untuk wilayah kota Banda Aceh dan Aceh Besar. Dalam penelitian ini bahan aditif yang digunakan adalah aspal emulsi. Aspal emulsi merupakan salah satu bahan yang digunakan untuk pembuatan jalan sehingga dapat dengan mudah dijumpai, selain itu berdasarkan literature (Bina Marga)[1] dan penelitian terdahulu (Nugroho[2] dan Diana dkk[3] ) aspal emulsi dapat digunakan untuk stabilisasi yaitu meningkatkan nilai CBR. Aspal emulsi yang digunakan adalah jenis CSS-1h (Cationic slow setting) berasal dari PT. Perdana Dinamika Persada Kecamatan Indra Puri Kabupaten Aceh Besar.

Penelitian ini bertujuan untuk mengetahui pengaruh penambahan aspal emulsi yang digunakan sebagai bahan stabilisasi terhadap nilai CBR tanah Desa Glee Geunteng Aceh Besar.

\section{Tinjauan Kepustakaan \\ 2.1 Klasifikasi Tanah}

Terdapat dua sistem klasifikasi yang sering digunakan dalam ilmu geoteknik yaitu USCS (Unified Soil Classification System) dan AASHTO (American Association of State Highway and Transportation Official). Kedua sistem klasifikasi ini secara umum menggunakan gradasi butiran dan sifatsifat plastisitas tanah sebagai dasar pembentukan klasifikasi.

\subsection{Stabilisasi}

Hardiyatmo[4] menyatakan stabilisasi kimiawi atau stabilisasi dengan menggunakan bahan tambahan dilakukan dengan cara mencampur tanah dengan bahan tambahan (additive) seperti kapur, semen portland, abu-terbang (fly ash) dan lainnya dengan perbandingan tertentu untuk memperbaiki sifat-sifat teknis tanah seperti kekuatan, tekstur, plastisitas serta kemudahan dalam pengerjaan, dan pada penelitian ini dilakukan stabilisasi kimiawi. Tujuan stabilisasi adalah untuk mendapatkan tanah dasar yang stabil pada semua kondisi dengan cara memperbaiki sifat teknis tanah seperti kuat geser, konsolidasi, CBR dan lain-lain.

\subsection{Aspal Emulsi}

Susanto [5] menyatakan Emulsi adalah dispersi suatu jenis cairan di dalam jenis cairan yang lain yang tidak saling melarutkan. Aspal emulsi merupakan dispersi bitumen dalam air yang dibuat stabil dengan penambahan emulsifier, Bentuk fisik dari aspal emulsi adalah cair, dingin dan berwarna coklat. Leksminigsih[6] menyatakan variasi persen bahan baku aspal emulsi adalah aspal $65 \%$, kerosene $2,8 \%$, emulsifier $0,48 \%$, $\mathrm{HCI} 0,48 \%, \mathrm{CaCl}_{2} 0,3 \%$ dan air $30,94 \%$, Secara garis besar emulsi dibedakan atas emulsi kationik dan emulsi anionik. Emulsi kationik bermuatan listrik positif dan emulsi anionik bermuatan listrik negatif.

Aspal emulsi yang diproduksi PT Perdana Dinamika Persada termasuk jenis CSS-1h (Cationic slow setting). SNI 4798[7] mengemukakan aspal emulsi jenis CSS-1h (Cationic slow setting) adalah aspal emulsi kationik (bermuatan positif) yang aspalnya memisah dari air secara lambat setelah kontak dengan agregat.

\subsection{Pemadatan}

Uji kepadatan dilakukan untuk menentukan hubungan kadar air dan berat volume serta mengevaluasi tanah agar memenuhi persyaratan kepadatan. Pengujian dilakukan dengan menggunakan sebuah tempat berbentuk silinder dan palu penumbuk standar, yang dalam penelitian ini digunakan standar proctor.

\subsection{Pengujian CBR (California Bearing Ratio)}

Wesley [8] menyatakan CBR adalah alat ukur penetrasi suatu piston standar yang pada daerah ujungnya mempunyai luas 3 inci $^{2}$, kemudian dipenetrasikan ke dalam tanah dengan kecepantan 0,05 inci/menit. Nilai CBR dihitung berdasarkan pada penetrasi 0,1 inci dan 0,2 inci dengan cara membagi beban pada masing-masing dengan beban 3000 pound dan 4500 pound. Beban ini adalah beban standar yang diperoleh dari percobaan terhadap batu pecah California yang mempunyai CBR 100\%.

Menurut Sukirman [9] nilai CBR yang digunakan adalah nilai CBR yang terbesar pada penetrasi 0,1 atau 0,2 inci. Untuk menghitung nilai CBR pada penetrasi 0,1 inci dan 0,2 inci dengan persamaan berikut;

$$
\begin{aligned}
& \mathrm{CBR}=\frac{\text { Beban Test }}{\text { Beban Standar }} \times 100 \% \% \ldots \ldots \ldots \ldots . . . . . \\
& \mathrm{CBR}_{0,1}=\frac{\text { Nilai Beban pada } 0,1 \text { inci }}{3000 \mathrm{lb}} \times 100 \% . \\
& \mathrm{CBR}_{0.2}=\frac{\text { Nilai Beban pada } 0,2 \text { inci }}{4500 \mathrm{lb}} \times 100 \% .
\end{aligned}
$$

Kaifan [10] mengemukakan bahwa besarnya nilai CBR adalah perbandingan antara beban yang diperlukan untuk mencapai penetrasi tertentu dengan pembebanan standar yang diperlukan untuk 
mencapai penetrasi yang sama. Tabel 1 berikut ini memperlihatkan beban-beban standar yang disesuaikan menurut penetrasi untuk material standar dengan nilai $100 \%$.

Tabel 1. Beban Standar pada Berbagai Penetrasi

\begin{tabular}{cccc}
\hline \multicolumn{2}{c}{ Penetration of Plunger } & \multicolumn{2}{c}{ Standard Load } \\
\hline Inchi & $\mathrm{mm}$ & $\mathrm{Lb}$ & $\mathrm{kg}$ \\
\hline 0,1 & 2,5 & 3000 & 1370 \\
0,2 & 5,0 & 4500 & 2055 \\
0,3 & 7,5 & 5700 & 2630 \\
0,4 & 10,0 & 6900 & 3180 \\
0,5 & 12,5 & 7800 & 3600
\end{tabular}

\section{Sumber[10]}

Grafik beban penetrasi yang diperoleh dari hasil pengujian CBR berupa garis lurus pada penetrasi rendah dan garis lengkung cembung pada penetrasi tinggi.

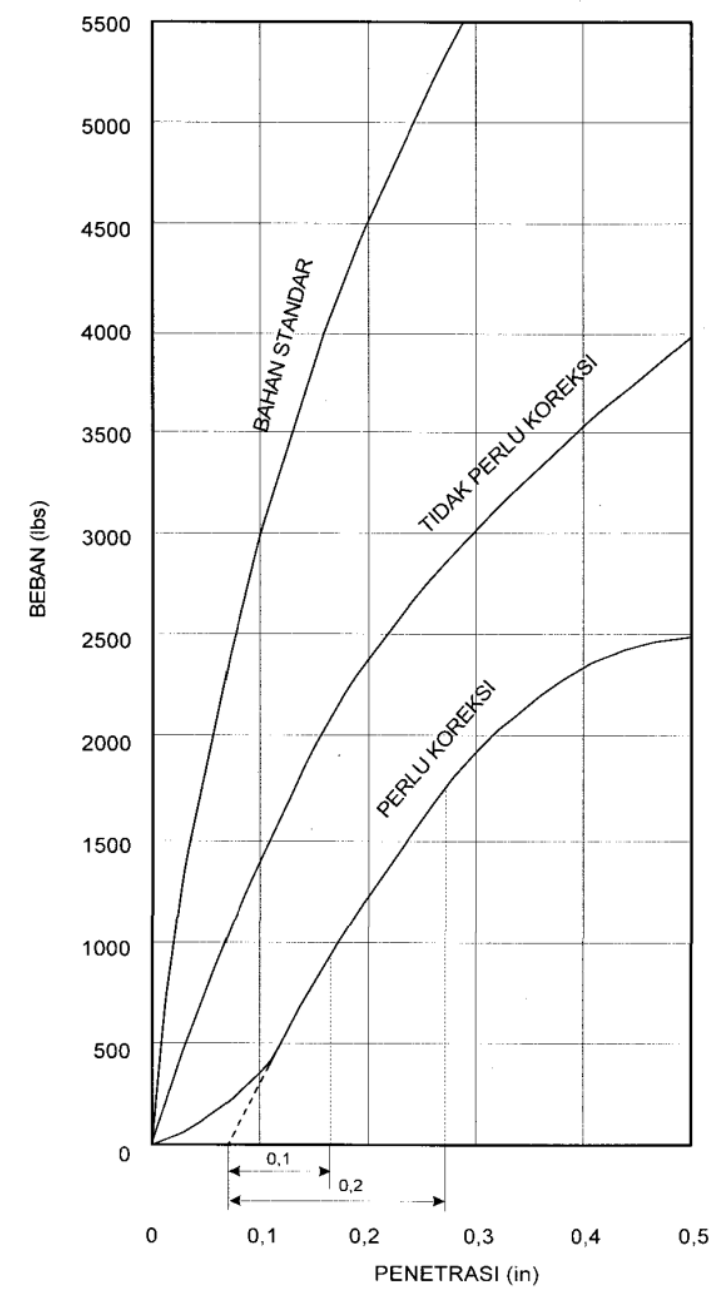

Gambar 1 Grafik Beban-Penetrasi dan koreksi kesalahan

Sumber [10]

\subsection{Penelitian Terdahulu}

Beberapa penelitian terkait stabilisasi tanah dengan bahan aspal emulsi telah dilakukan oleh beberapa peneliti yang melihat pengaruhnya terhadap nilai CBR, penurunan konsolidasi dan modulus elastisitas tanah serta kembang susut dan daya dukung tanah ekspansif. Berikut ini diuraikan beberapa hasil penelitian terkait stabilisasi tanah menggunakan aspal emulsi.

1. Susanto (2009) telah meneliti pengaruh penambahan aspal emulsi dengan variasi $0 \%$, $3 \%$, 6\%, 9\%, dan $12 \%$ terhadap penurunan konsolidasi dan modulus elastisitas tanah pada tanah lempung Kedungsari Wates Yogyakarta. Dari hasil penelitian diketahui bahwa nilai modulus elastisitas mengalami kenaikan tertinggi pada penambahan aspal emulsi $6 \%$ dari berat kering tanah yaitu dari $91,95 \mathrm{~kg} / \mathrm{cm}^{2}$ menjadi $250,2 \mathrm{~kg} / \mathrm{cm}^{2}$ dan memperkecil nilai indeks pemampatan (Cc) dari 0.314 menjadi 0,232 berarti memperkecil penurunan sebesar $26,27 \%$.

2. Nugroho (2003) telah meneliti pengaruh penambahan kapur dan aspal emulsi tehadap kembang susut dan daya dukung tanah ekspansif sebagai subgrade jalan dengan variasi campuran untuk kapur $0 \%, 4 \%$, dan $8 \%$ sedangkan untuk aspal emulsi $0 \%, 4 \%, 6 \%$ dan $8 \%$. Variasi pemeraman diakukan dalam 0 hari, 2 hari, 4 hari dan 7 hari. Pada tanah lempung Desa Polokulon Grobongan $3 \mathrm{Km}$ dari arah barat kota Purwodadi. Hasil penelitian menunjukan bahwa peningkatan konsentrasi aspal emulsi dan masa pemeraman mengalami peningkatan nilai CBR dan begitu pula untuk bahan kapur.

3. Diana dkk (2011) telah meneliti pengaruh penambahan aspal terhadap nilai CBR dengan variasi $0 \%, 1 \%, 2 \%, 3 \%, 4 \%$, dan $5 \%$ pada tanah Pantai Glagah, Kulon Progo, Daerah Istimewa Yogyakarta. Hasil penelitian yang diperoleh adalah nilai CBR maksimum diperoleh pada kadar aspal $2 \%$ dari $8 \%$ menjadi $20 \%$ (peningkatan sebesar 150\%). CBR cenderung turun pada kadar aspal 3\% sampai $5 \%$ dikarenakan campuran tanah dan aspal menjadi bersifat lebih plastis. Tanah kehilangan kekuatan akibat efek pelumasan oleh aspal.

\section{Metode Penelitian}

Pada bagian ini dijelaskan mengenai uraian yang berkaitan dengan objek penelitian, jenis dan sumber data, teknik pengumpulan data serta teknik analisis. Untuk lebih jelasnya dapat dilihat pada bagan alir penelitian berikut ini. 
3.1 Alur Penelitian
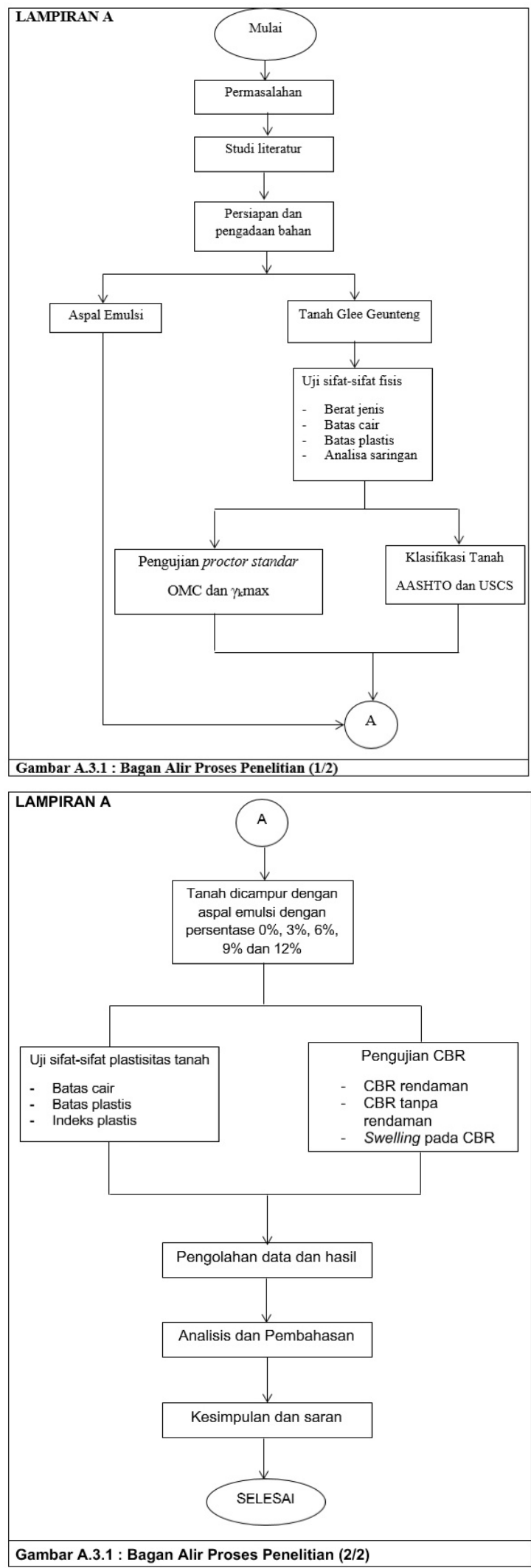

Gambar 2 Bagan Alir

\subsection{Objek Penelitia}

Tanah yang digunakan pada penelitian ini berasal dari desa Glee Geunteng, Kecamatan Peukan Bada, Kabupaten Aceh Besar. Aspal emulsi diperoleh dari
PT. Perdana Dinamika Persada, Kecamatan Indra Puri, Kabupaten Aceh Besar dengan perentase campuran aspal emulsi $0 \%, 3 \%, 6 \%, 9 \%$ dan $12 \%$.

\subsection{Jenis dan Sumber Data}

Data yang diperlukan dalam penelitian ini meliputi data primer dan data sekunder. Data primer adalah data utama yang diperlukan dalam analisis hasil penelitian, data ini diperolah dari hasil pemeriksaan atau pengujian langsung di laboratorium. Data sekunder merupakan data pendukung yang diperlukan dalam penelitian di antaranya yaitu, angka koreksi benda uji pada saat perhitungan, angka kalibrasi alat uji, serta peta lokasi pengambilan tanah dan lain sebagainya. Data sekunder diperoleh dari instansi-instansi terkait, studi literatur dan konsultasi.

\subsection{Teknik Pengumpulan Data}

Teknik pengumpulan data mencakup pengambilan sampel tanah, pengukuran sifat-sifat fisis, pembuatan benda uji, pemadatan, dan pengujian CBR (California Bearing Ratio). Penelitian ini dilakukan dengan berbagai variasi campuran aspal emulsi untuk mendapatkan gambaran tentang stabilisasi yang baik pada tanah campuran.

\section{Hasil dan Pembahasan}

Hasil penelitian dan pengolahan data yang disajikan meliputi pengujian sifat-sifat fisis berupa berat jenis, batas cair, batas plastis, pembagian butir, klasifikasi tanah berdasarkan AASHTO dan USCS. Pengujian sifat mekanis yaitu pemadatan (Standard Proctor) dan pengujian CBR (California Bearing Ratio)

\subsection{Hasil Pengujian Sifat-sifat Fisis Tanah}

Berdasarkan penelitian yang telah dilakukan terhadap tanah Desa Glee Geunteng Kecamatan Peukan Bada Kabupaten Aceh Besar didapatkan hasil sifat-sifat fisis tanah yang terdiri dari berat jenis, batas cair, batas plastis, dan analisa saringan. Hasil pengujian sifat-sifat fisis tanah diperlihatkan dalam Tabel 2 . berikut ini.

Tabel 2. Hasil Pengujian Sifat-sifat Fisis Tanah

\begin{tabular}{clc}
\hline No & Parameter Pengujian & $\begin{array}{c}\text { Tanah Tanpa } \\
\text { Campuran }\end{array}$ \\
\hline 1 & Berat Jenis & 2,67 \\
\hline 2 & Batas Cair (\%) & 28,92 \\
\hline 3 & Batas Plastis (\%) & 16,27 \\
\hline 4 & Indeks Plastis (\%) & 12,65 \\
\hline 5 & Lolos Saringan \# 200 (\%) & 42,85 \\
\hline
\end{tabular}

\subsection{Klasifikasi Tanah Menurut AASHTO dan USCS}

Klasifikasi menurut AASHTO dilakukan berdasarkan hasil analisa saringan dan pengujian 
sifat fisis tanah. Data dari hasil pengujian dapat dilihat pada Tabel 2 menunjukan bahwa tanah yang lolos saringan nomor 200 (diameter $0,074 \mathrm{~mm}$ ) adalah $42,85 \%$ lebih dari $35 \%$, sehingga tanah tersebut termasuk tanah lanau-lempung dengan simbol kelompok A-4, A-5, A-6, dan A-7. Berdasarkan pengujian sifat fisis diperoleh batas cair (LL) $28,92 \%$, kurang dari $40 \%$ dan indeks plastis $12,5 \%$ yang lebih besar dari $11 \%$, maka tanah tersebut dimasukan kedalam kelompok A-6. Kualitas tanah tersebut dapat ditentukan berdasarkan indeks kelompoknya. Indeks kelompok ditentukan dari nilai batas cair, indeks plstis dan persentase butiran yang lolos saringan 200, dengan menggunakan persamaan berikit ini.

$\mathrm{GI}=(\mathrm{F}-35)[0,2+0,005(\mathrm{LL}-40)]+0,01(\mathrm{~F}-15)(\mathrm{PI}-10)$

$\mathrm{GI}=(42,85-35)[0,2+0,005(28,92-40)]+0,01$

$(42,85-15)(12,65-10)$

$\mathrm{GI}=1,87$

Maka diperoleh indeks kelompoknya 1,87 atau dibulatkan menjadi 2. Berdasarkan nilai-nilai tersebut maka tanah Glee Geunteng termasuk tanah lempung berpasir yang tergolong kedalam kelompok A-6 (2).

Penentuan jenis tanah menurut sistem USCS didasarkan pada analisis saringan, batas cair dan batas plastis. Berdasarkan analisa saringan menunjukan bahwa tanah yang lolos saringan nomor 200 sebesar $42,85 \%$ yaitu kurang dari $50 \%$ sehingga tanah tersebut dimasukan kedalam tanah berbutir kasar, dengan menggunakan analisa saringan lolos saringan nomor 200 sebesar $42,85 \%$ dan indeks plastisnya $12,65 \%$ lebih besar dari $7 \%$, maka tanah tersebut digolongkan kedalam kelompok SC, pasir berlempung bergradasi buruk.

Tabel 3. Hasil Klasifikasi tanah menurut AASHTO dan USCS

\begin{tabular}{ccc}
\hline \multirow{2}{*}{ Objek } & \multicolumn{2}{c}{ Sistem Klasifikasi } \\
Tanah & AASHTO & USCS \\
Glee & A-6 (2) & SC ( Sand Clay) \\
& $\begin{array}{c}\text { Tanah } \\
\text { berlempung } \\
\text { dengan } \\
\text { plastisitas } \\
\text { rendah sampai } \\
\text { sedang }\end{array}$ & $\begin{array}{c}\text { Pasir } \\
\text { berlempung } \\
\text { campuran }\end{array}$ \\
& & $\begin{array}{c}\text { Pasir-lempung } \\
\text { bergradasi buruk }\end{array}$ \\
\hline
\end{tabular}

\subsection{Pemadatan}

Tanah yang digunakan pada pengujian ini adalah tanah dalam keadaan kering udara yang lolos saringan nomor 4 (4,76 mm). Sampel tanah disiapkan dalam kantong plastik sebanyak 5 buah dengan berat masing-masing 2000 gram, kemudian diberikan air dengan rencana kadar air yang berbeda. Tanah bersama air diaduk hingga merata dan dimasukkan ke dalam kantong plastik untuk menjaga kadar airnya. Tanah tersebut didiamkan selama 24 jam agar air meresap secara merata ke dalam tanah. Selanjutnya akan dilakukan pemadatan untuk memperoleh kadar air optimum OMC (Optimum Moisture Content) dan berat volume kering maksimum $\left(\gamma_{\mathrm{d}} \max \right)$. Berat volume kering tanah diperoleh dari perbandingan antara berat volume basah dengan kadar air sedangkan kadar air diperoleh dari rata-rata kadar air bagian atas, tengah dan bawah pada setiap benda uji. Pemadatan dilakukan dengan menjatuhkan hammer ke dalam mold yang telah diisi tanah kira-kira $1 / 3$ bagian mold sebanyak 25 kali setiap lapisan, di mana untuk setiap mold dipadatkan sebanyak 3 lapisan. Hasil pengujian pemadatan diperlihatkan pada Gambar 3 dan Tabel 4.

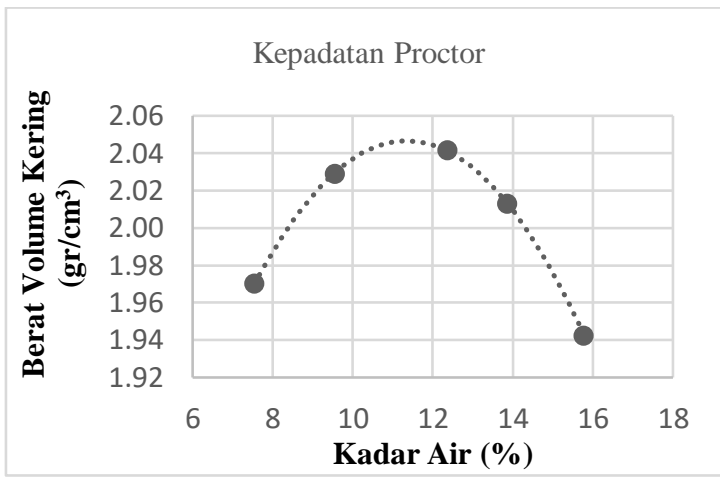

Gambar 3 Grafik Hubungan Berat Volume Kering maksimum dengan kadar air

Tabel 4. Hasil Pengujian Pemadatan

\begin{tabular}{cc}
\hline $\begin{array}{c}\text { Berat volume kering } \\
\text { maksimum } \\
\gamma_{\mathrm{d} \mathrm{mak}},\left(\mathrm{gr} / \mathrm{cm}^{3}\right)\end{array}$ & $\begin{array}{c}\text { Kadar air } \\
\text { optimum } \\
(\%)\end{array}$ \\
\hline 2.048 & 11.37 \\
\hline
\end{tabular}

\subsection{Hasil pengujian Sifat Plastisitas Tanah} dengan Persentase Campuran Aspal Emulsi

Berdasarkan pengujian yang telah dilakukan diperoleh hasil sifat plastisitas tanah yang terdiri dari batas cair (LL), batas plastis (PL) dan indeks plastis (PI), dengan persentase campuran aspal emulsi $0 \%$, 3\%, 6\%, 9\% dan 12 dapat dilihat dalam Tabel 5.

Tabel 5. Hasil Pengujian Sifat Plastisitas Tanah dengan Perentase Campuran Aspal Emulsi

Persentase

campuran Batas-batas Atterberg (\%) 


\begin{tabular}{cccc} 
Aspal Emulsi & $\begin{array}{c}\text { Batas } \\
\text { Cair }\end{array}$ & $\begin{array}{c}\text { Batas } \\
\text { Plastis }\end{array}$ & $\begin{array}{c}\text { Indeks } \\
\text { Plastis }\end{array}$ \\
\hline 0 & 28,92 & 16,27 & 12,65 \\
\hline 3 & 30,38 & 16,75 & 13,64 \\
\hline 6 & 30,80 & 16,86 & 13,94 \\
\hline 9 & 32,93 & 16,96 & 15,97 \\
\hline 12 & 36,94 & 17,45 & 19,49 \\
\hline
\end{tabular}

\begin{tabular}{cc}
\hline 3 & 22,02 \\
\hline 6 & 17,54 \\
\hline 9 & 12,99 \\
\hline 12 & 8,71 \\
\hline
\end{tabular}

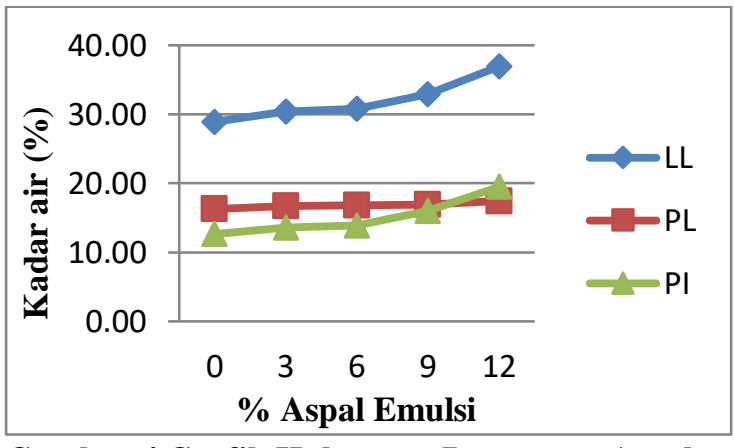

Gambar 4 Grafik Hubungan Persentase Aspal Emulsi dengan Sifat Plastisitas

Dari Tabel 5 dan Gambar 4 di atas memperlihatkan bahwa penambahan aspal emulsi pada tanah Glee Geunteng meningkatkan batas plastis relatif kecil dan secara signifikan meningkatkan batas cair sehingga indeks plastis tanah yang merupakan pengurangan antara nilai batas cair dan batas plastis mengalami kenaikan juga.

\subsection{Hasil Pengujian CBR (California Bearing Ratio)}

Pembacaan pembebanan dicatat pada penetrasi: 0,$0125 ; 0,025 ; 0,05 ; 0,075 ; 0,10 ; 0,15 ; 0,20 ; 0,30$; 0,40 ; dan 0,50 inci pada kedua permukaan tanah dan bawah dari benda uji. Setelah proses pembebanan selesai, benda uji dikeluarkan dari cetakan dan kemudian diukur kadar airnya. Angka baca proving ring selanjutnya dikalikan dengan angka kalibrasi untuk mendapatkan nilai beban pengujian CBR. Hasil percobaan ini kemudian diplot ke dalam sebuah grafik hubungan penetrasi (inci) dengan beban $(l b)$. Nilai beban ini dibaca pada penetrasi 0,1 dan 0,2 inci yang dibagi dengan beban standar pengujian CBR dan dikalikan dengan $100 \%$ seperti diuraikan pada persamaan 2.2 dan 2.3. Hasil pengujian CBR dapat dilihat pada Tabel 6 dan Gambar 4 berikut ini.

Tabel 6. Hasil Pengujian CBR

\begin{tabular}{cc}
\hline $\begin{array}{c}\text { Persentase campuran } \\
\text { Aspal Emulsi }\end{array}$ & Nilai CBR $(\%)$ \\
\hline 0 & 35,96 \\
\hline
\end{tabular}

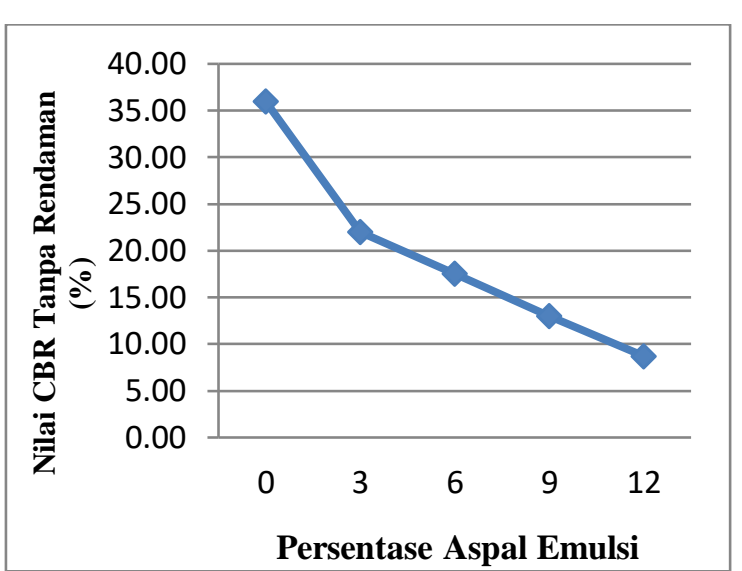

Gambar 5 Grafik Hubungan Persentase Aspal Emulsi dengan Nilai CBR

Hasil pengujian menunjukan setelah penambahan aspal emulsi nilai CBR mengalami penurunan, pola hubungan antara campuran aspal emulsi dengan nilai CBR secara jelas dapat dilihat pada Tabel 6 dan Gambar 5. Penambahan aspal emulsi dengan persentase campuran $0 \%, 3 \%, 6 \%, 9 \%$ dan $12 \%$ ternyata dapat mempengaruhi nilai CBR. Pola hubungan antara campuran aspal emulsi dengan nilai CBR yang dapat dilihat pada Gambar 5 menunjukan bahwa nilai CBR menurun dengan bertambahnya persentase aspal emulsi.

Hasil pengujian CBR pada tanah asli (0\%) diperoleh sebesar $35,96 \%$, pada penambahan $3 \%$ aspal emulsi nilai CBR turun menjadi $22,02 \%$, pada penambahan $6 \%$ aspal emulsi nilai CBR turun menjadi $17,54 \%$, pada penambahan $9 \%$ aspal emulsi nilai CBR turun menjadi $12,99 \%$ dan pada penambahan $12 \%$ aspal emulsi nilai CBR juga turun menjadi $8,71 \%$. Penurunan paling tajam perjadi pada campuran $3 \%$ pertama aspal emulsi, penurunan terjadi sebesar $38,77 \%$ dan pada persentase seterusnya penurunan terjadi rata-rata sebesar $26,41 \%$ untuk setiap tambahan capuran $3 \%$.

Membandingkan hasil penelitian ini dengan penelitian terlahulu menunjukan hampir sejalan dengan Diana dkk (2011) yang menyatakan bahwa nilai CBR meningkat pada campuran aspal emulsi $1 \%$ dan $2 \%$ kemudian turun pada campuran yang lebih besar mulai dari 3\%, 4\% dan 5\% campuran aspal emulsi. Pada penelitian ini karena campuran aspal emulsi dimulai dari 35 sampai $12 \%$, maka kondisi pada campuran 15 dan $2 \%$ tidak terlihat.

\section{Kesimpulan dan Saran \\ 5.1 Kesimpulan}

Beberapa kesimpulan yang diperoleh dari penelitian ini adalah sebagai berikut. 
1. Tanah Glee Geunteng Kecamatan Peukan Bada Kabupaten Aceh Besar termasuk ke dalam pasir berlempung bergradasi buruk (SC) menurut USCS dan tergolong A-6 (2) menurut sistem AASHTO;

2. Penambahan persentase aspal emulsi dari $3 \%$ sampai $12 \%$ pada tanah Glee Geunteng dapat meningkatkan sifat plastisitas tanah.

3. Hasil pengujian CBR pada campuran aspal emulsi dari $3 \%$ sampai $12 \%$ ternyata menurunkan nilai CBR.

4. Penambahan aspal emulsi berpengaruh terhadap karakteristik tanah Glee Geunteng yaitu dengan peningkatan nilai plastisitas tanah, penurunan nilai CBR.

\subsection{Saran}

Untuk penelitian selanjutnya disarankan untuk tidak menggunakan aspal emulsi sebagai bahan stabilisasi, dikarenakan pada aspal emulsi tidak ada komponen seperti yang terdapat pada semen, yang dapat mengikat butir-butir tanah yang berpengaruh terhadap peningkatan kekuatan.

\section{Daftar Kepustakaan}

[1] Anonim. Modul 1-3, Perencanaan Penggunaan Aspal Emulsi untuk Perkerasan Jalan, Bina Marga Departemen PU, Jakarta, 1998.

[2] Nugroho, U. Pengaruh Penambahan Kapur dan Aspal Emulsi Terhadap Kembang Susut dan Daya Dukung Tanah Ekspansif Sebagai Subgrade Jalan, Fakultas Teknik Universitas Diponogoro, Semarang, 2003.

[3] Diana, W. A. Marianti, I. Ernawati. Optimasi Kadar Aspal pada Stabilisasi Tanah Pasir Menggunakan Aspal dengan Uji CBR, Fakultas Teknik, Universitas Muhammadiyah Yogyakarta, Bantul, 2011.

[4] Hardiatmo, H. C. Stabilisasi Tanah Untuk Perkerasan jalan, Penerbit Universitas Gajah Mada, Yogyakarta, 3013.

[5] Susanto, A. Pengaruh Stabilisasi Tanah Lempung Dengan Aspal Emulsi Terhdap Penurunan Konsolodasi dan Modulus Elastisitas Tanah, Fakultas Teknik Universitas Muhammadiyah Surakarta, Kartasura, 2009.

[6] Leksminingsih. Pembuatan Aspal Emulsi Yang Tahan-Simpan, Puslitbang Teknologi Prasarana Transportasi, Bandung, 2000.

[7] SNI 4798. Sepesifik Aspal Emulsi Kationik, 2011.

[8] Wesley, L. D. Mekanika Tanah, Cetakan keenam, Badan Penerbit pekerjaan umum, Jakarta, 1977.

[9] Sukirman, S. Perkerasan Lentur Jalan Raya, Bandung, 1995.

[10] Kaifan, A. Penggaruh Pencampuran Bubukan Bata Merah dan Semen Terhadap Nilai CBR
Tanah Desa Cot Masam, Fakultas Teknik Universitas Syiah Kuala, Banda Aceh, 1998. 